\title{
Retraction Note to: Aging decreases rate of docosahexaenoic acid synthesis-secretion from circulating unesterified $\alpha$-linolenic acid by rat liver
}

\author{
Fei Gao • Ameer Y. Taha • Kaizong Ma • Lisa Chang • \\ Dale Kiesewetter $\cdot$ Stanley I. Rapoport
}

Published online: 12 April 2014

(C) American Aging Association 2014

\section{Erratum to: Age (2012) 35(3): 597-608 \\ DOI 10.1007/s11357-012-9390-1}

This article has been retracted by the authors as they were unable to reproduce some of the data and therefore consider them unreliable.

To the editor of Age:

The NIH found that Dr. Fei Gao engaged in research misconduct by fabricating and/or falsifying data in
Figures 1-7 and Table 2 in "Aging decreases rate of docosahexaenoic acid synthesissecretion from circulating unesterified $\alpha$-linolenic acid by rat liver. Gao F, Taha AY, Ma K, Chang L, Kiesewetter D, Rapoport SI. Age (Dordr). 2012 Mar 3," and therefore I request a full retraction of this paper. Please note, none of the other authors were implicated in any way.

Stanley I. Rapoport

The online version of the original article can be found at http://dx. doi.org/10.1007/s11357-012-9390-1.

F. Gao $\cdot$ A. Y. Taha $\cdot$ K. Ma $\cdot$ L. Chang $\cdot$ S. I. Rapoport Brain Physiology and Metabolism Section, National Institute on Aging, National Institutes of Health,

Bethesda, MD 20892, USA

D. Kiesewetter

Laboratory of Molecular Imaging and Nanomedicine,

National Institute of Biomedical Imaging and Bioengineering,

National Institutes of Health,

Bethesda, MD 20892, USA

F. Gao $(\bowtie)$

Center for Experimental Therapeutics and Reperfusion Injury, Brigham and Women's Hospital, Harvard Medical School,

77 Avenue Louis Pasteur, Boston, MA 02115, USA

e-mail: fgao1@partners.org 